\title{
Shepherd's Oral Poetry Creativity, Performance, Transmission and Content Analysis in South Wollo Zone, Ethiopia
}

\author{
Almaz Zewdu Akalu \\ Ethiopian Biotechnology Institute, Department Of Public and International Relation, P.O.Box 5954, Addis \\ Ababa, Ethiopia
}

\begin{abstract}
This study was conducted on Shepherd's oral poetry in the Northern part of Ethiopia, South Wollo Zone, Legambo Woreda. It aimed to describe the creativity, performance, transmission of the poets' poems, to analyze the content, show their imagination and philosophy of life. The study design was mainly focus on performance based and the data presentation was on descriptive analytical methods. The results of the study showed that the shepherds create and transmit verbal, phrasal and grammatical oral poetry that are sung and arranged depending on the contextual settings. The findings have shown that shepherds create their oral poems and sing them individually, in pairs, and in groups. In addition to composing oral poetry for various social, political and economic issues, shepherds use it as criticism and prophecy to forecast the upcoming events. Shepherds are considered as "prophets" in the community. The local community usually eager to hear and ask frequent questions like, "What did the shepherd say?" The findings of the current study have proven that shepherds have given high dignity best owed in the community by their great poems. The community point out that their talents are unique and are the result of a genetic inheritance.
\end{abstract}

Keywords: oral poetry, creativity, performance, transmission, content analysis.

DOI: $10.7176 / \mathrm{ADS} / 91-01$

Publication date:March $31^{\text {st }} 2021$

\section{Introduction}

Oral poetry is a verbal poem; spoken or transmitted orally; everywhere regardless of time, society and situation. It is a huge resource which is a reflection of people's attitudes, feelings, desires and philosophies that can be said and heard beyond space, time and circumstances.

Although rhetoric has been associated with oral poetry as if it is a character of backwardness and uneducated society, it has been and will continue to be used as a symbol of success failure, sadness, fear, respect and admiration of success and failure in any generation and society. Thus, there is no doubt that poetry could not be out-of-date and is universal. In this regard, Finnegan $(1977,3)$ said that it is to be practiced and performed in many areas of the world. A comparative perspective can led top awareness of the complexity and diversity of forms throughout human culture and history and cast doubt on some crude dichotomies used by social scientists in the past that between "civilized" as against primitive and "simple" society.In general she explains that oral poetry exists everywhere in the ancient as well as in the modern societies, regardless of time and space.

Oral poetry has many origins, performance techniques, methods of communication and hasmany advantages. It treats any party and community according to their needs and wishes; because poetry expresses a person's inner life and deep feelings as an expression of desire, thought, feeling, respect, and admiration. It is also used to provide information, used by the community to deal with potential dangers and to escape the consequences, both good and bad.

Thus, this study on oral poetryfocuses on the analysis of the creativity and content of poems sung by pastoralists in Legambo Woreda, South Wollo Zone, Northern Ethiopia. Agriculture and livestock are the main sources of livelihood for the people in Legambo Woreda. The area is home to a large number of livestock. In relation to livestock production, a wealthy farmer hires someone as shepherd, who is unable to support himself. There are three types of shepherds' employment. In the first type, payment is in terms of money or grain. The shepherd could receive his monthly or annual salary. If the child is under the age of 10, the family will collect the child's wages, "until he/she get matured". If a child is young and mature, he or she will receive it up. If the shepherd could do other things besides animal husbandry, the wage would also be increased. He will be paid according to his deeds.

The second type of employment is in the form of marriage. In this case the shepherd asks a daughter who is born in a rich family for married. If his inquiry is accepted, the shepherd will serve the family until the daughter gets matured and mean while he can accumulate wealth for the later marriage. This is called the "\$r hic" ("Qote Asir") in the local dialect. This type of employment is for men only. This is due to the fact that most of the field duties and animal protection work is done by men in the area and women participate in the house hold activities around homes. They say that this is what the culture taught us and we inherited it from our ancestors. The third type of employment requires the employer to provide all the needs of the employee including his school education, at the same time the shepherd is responsible to rear the livestock. 
Shepherds have two kinds of interactions. The first is their interaction with one another. From a distance, they exchanged greetings with a unique sound called "Wu Wu..." (" $\omega \cdot \omega \cdot ")$. After they meet in person, they used to joke, sing turn by turn, brag, play, and talk and so on. This strong bond exists not only in happiness but also in times of trouble. If one of them is get sick, they will take care of his cattle, if cattle are lost, they will search for it together. The other is their relationship with the rest of society. They also interact with the rest member of the community by participating and plough agricultural lands, caring for crops, weeding and harvesting etc.

The study site was selected because the shepherds in this particular area have unique oral poetry performance, which is different from all other areas in Ethiopia. The author has never come across a national or international study on the creativity, performance, transmission, and content analysis of oral poetry which could be comparable with Shepherd's in Legambo Woreda. Hence, this study believed to fills such gap and reflects a unique perspective and found to be powerful to draw attention.

\section{Research Methods and Procedures}

\subsection{Location}

The study was conducted in South Wollo, Legambo Woreda. South Wollo is one of 10 Zones in the Amhara National Region State of Ethiopia. Legambo Woreda is located $11^{\circ} 00$ North latitude and $39^{\circ} 00^{\prime}$ East Longitude (Figure 1). The elevation of this area is ranging from 1500 to 3700 meters above sea level. Dessie is the capital of south wollo, which is located $410 \mathrm{~km}$ far from Addis Ababa.

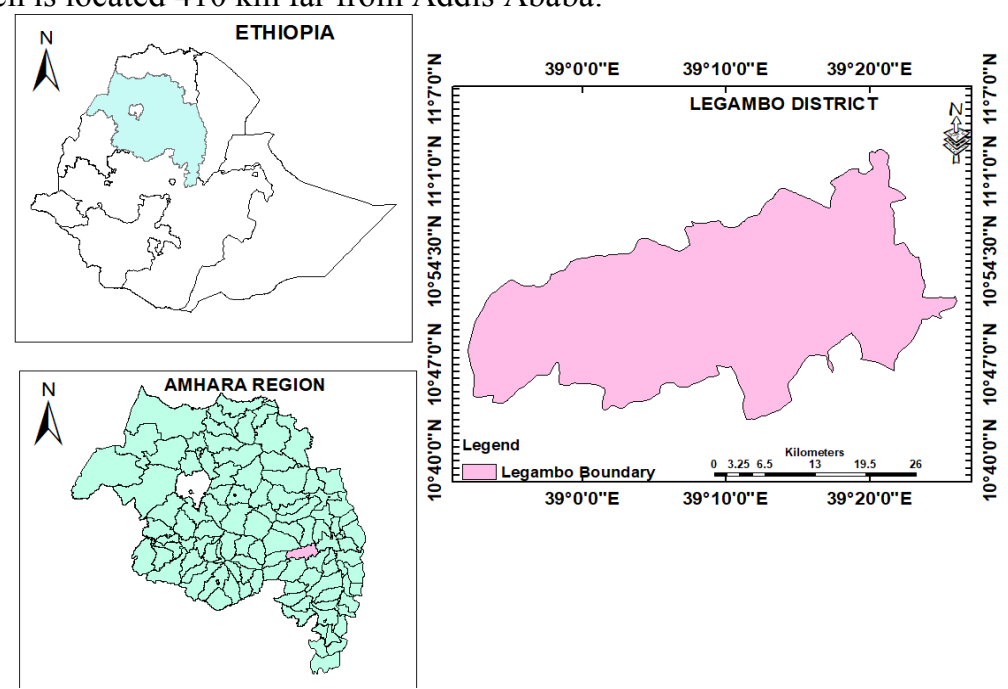

Figure 1; Map of the Study Aria

\subsection{Method of Data Collection}

The study participants were shepherds in Legambo Woreda various age levels including children, adolescents, and the elderly. This is because shepherds in the study area are often in these age ranges. Accordingly, the study included oral poetry used for song, lyrics, hymns, chants, brags and other poems created and performed by the shepherds.

Appropriate data for this study were collected from primary and secondary sources. Data collection began with secondary sources. The information was collected from libraries, textbooks from various offices and from community figure people who knew about the environment. Accordingly, textual and verbal information about the study environment and the general population, as well as theories used to analyze and organize the study were collected from various books.

Primary sources focus on the context in which the oral poetry were performed, the contextual informants, and the circumstances that led to the performance of the folklore Goldstein $(1964,80-82)$. Therefore, those individuals who provided information, phenomenon that enable to collect, organize and analyze the lyrics were considered a as primary sources of data. Hence, the data was collected from the real social context in natural and artificial settings.

In this study, observations and interviews were used mainly to collectthe data from primary sources. According to Fekade (1993) in a field work observation and interviews used to adequately collect data, fill information gaps, and enable to easily understand different perspectives and philosophies. Observation was used to collect oral poems from theircontextual settings. Hence it allowed the researcher to collect the oral poems from their natural contextual settings, processes of performance, pragmatic, and the role of the performer, used to compile the lyrics, the overall movement, and the interactions among themselves. This has given a better chance to understand and analyze the information in detail. 
According to Goldstein (1964) the information in the interview includes the views, feelings and interests of the informants, as well as explanations and description of the ideas. The use of interviews in this study also enabled the researcher to understand vague words and historical events during the observation.

Interviews were conducted more than twice as often as required. The first was pre-operation with key informants who were thought to have better knowledge and that was supposed to helpunderstand the general preoperation situation.

The second was after operation and observation. This was done by the performers without leaving the performance context and it was conducted with the individuals who were involved in the performance. In so doing, it was possible to get answers to all the ambiguities during the performance of poems. In addition, at various times, both before and after the performance, data was collected from various individuals while they were in various local cattle ranches.

Georges and Jones (1995) Fekade (1993) recommend that collection of data from the natural context using technology, enable one to collect the shapes, colors, patterns, melodies, movements, and other forms of folkloreentities which could not be recorded by write up. Based on the experience of these scholars, it was possible to gather information by tapping on a tape recorder, photo and video camera, and notebooks.

\subsection{Data analysis}

The study mainly uses performance based theory, including other theories as needed. Field data was analyzed using descriptive and analytical data analysis methods. Hence, the shepherd's oral poetry, their performance and the main content of the oral poetry was described and analyzed.

\section{Exploratory Aspects}

This section basically asks the meaning of shepherd, deals with the oral poetry composition, transmission, and focuses on the sense of performance which is the main pivotal point of the study, including the essence and style of the poem.

When it comes to shepherds, we think of the protection of cattle. What is a shepherd? This term has been interpreted by Kesate Berhan (1951) as "one who keeps cattle from going to the worst places." According to the definition, shepherding means keeping cattle in a pasture. It is well-known that when shepherds look after their cattle, they sing a song. Although they are part of the community, it is important to note that they have a unique vocabulary. Since shepherds are part of the community it might raise a question how they have a unique oral poetry, but in relation to their role they have a poem known as shepherd's oral poetry.

According to Fekade (1991) based on different criteria, it is common to refer to many poems as mourning, wedding, epiphany, harp, ark and shepherd's oral poetry. These names are given to the reason for the performance, the songwriter, the instrument, and in relation to the singer. Thus, according to Fekad, the word "shepherd's oral poetry" is used in connection with the actions of the singers or in relation to their roles. Shepherds are not only a part of the community but also a breath of fresh air. This is because they disseminate untouchable issues (concerns in which the community fears to speak out), to the large society using their oral poetry.

\subsection{Performance}

Two things are needed to accomplish something, the actor and spectator/ audience. To study and understanding the interaction between these two subjects is a major task for folklore experts. What do we mean by performance? According to Martha C. Sims (2005) performance is an expressive activity that demand participation, heightens our enjoyment of experience, and invites response. In order for a performance to "happen," a recognized setting must exist (we have to know a performance is taking place) and participants (performers and audience) must be present. The details of the setting and relationships between participants can be quitecomplex and fluid, but all participants understand that they are engaged in some kind of performance activity.

As we can see from the quote, performance is any fun and engaging activity that involves actors and spectators. Every spectator should look at the movement and competence of people on stage in terms of the culture and tradition of the community in which they present their work. Otherwise, the performer's idea and message may not be as complex and complete. Performance is a guarantee whether the lyrics performed individually or in groups. In this regard, Fekade authorized that the guarantee for word of mouth is performance. It is passed down from generation to generation by descending from the author and to the audience by speaking, singing, narrating, and playing the harp. If word of mouth is not performed in public or in the way it is performed, then it does not exist. If left unmanaged, it can be left astray and lose the right path On the other hand, Finnegan (1977), said that "since, an oral poem is an essentially ephemeral work of art and has no existence or continuity apart from its performance." Both authors tell us that for the existence of oral poetry, performance is not only decisive factor but also a blood vessel. Unless a lot of word poems are performed (unless sung, danced, spoken and presented for audience), there is no alternative to pass it on to the next generation. Only when it is 
performed, it can make the audience sad and happy. Therefore, oral poetry and performance should not be seen as separate; however, if they were separated, they would not be alive

Although there are different types of oral poems, all poems have their own performance according to their characteristics. According to Fekade (1984) Finnegan (1974) Finnegan (1977) and Bauman (1977) the performance setting, audience, performers, text, etc., vary according to their own character and function. This shows us that, as performance is the guarantee for the existence of oral poetry, it can have its own anchoring elements. These are primarily performers, context, audience, setting, formula, message and rule. These elements of performance are strongly interrelated and inseparable.

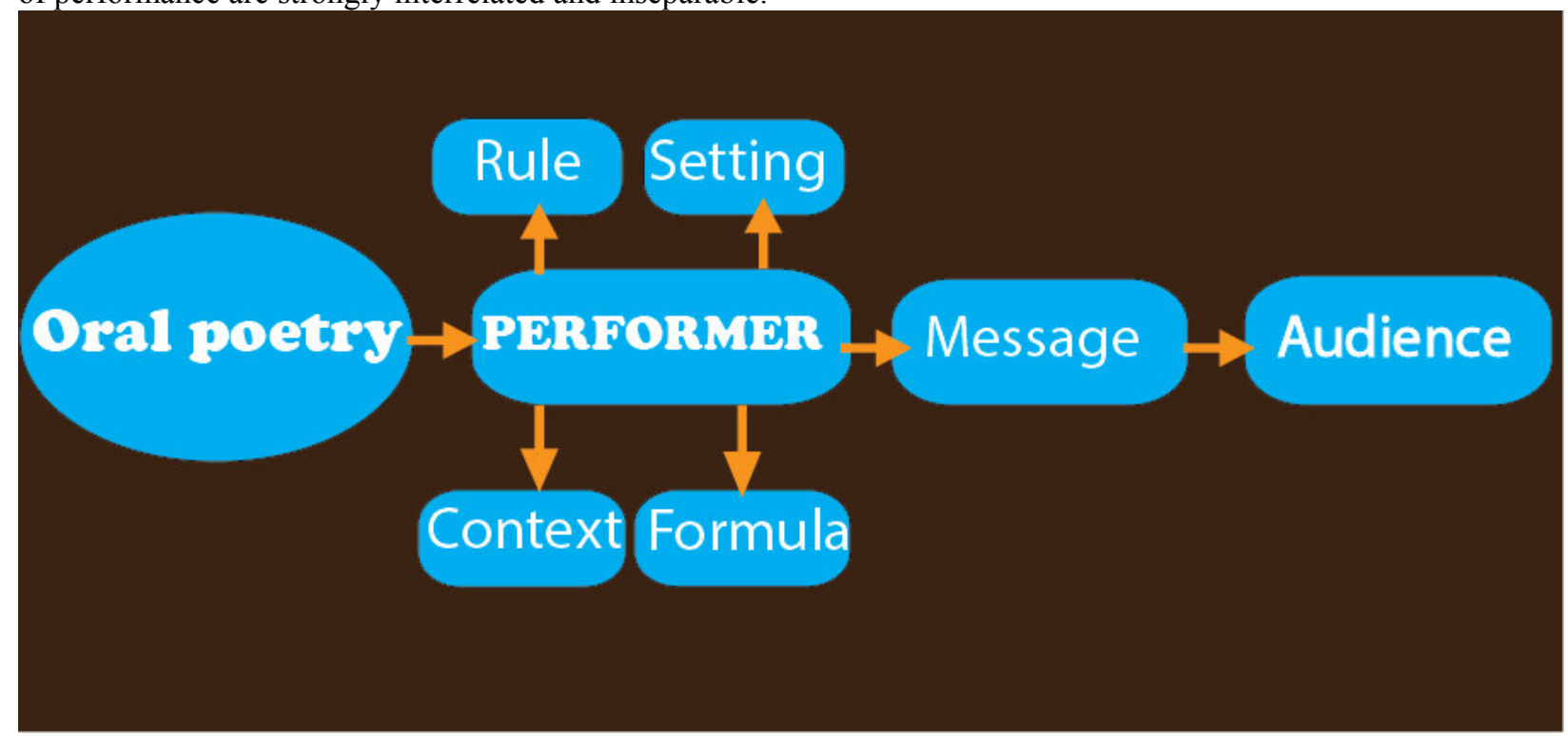

Figure 2 .Shepherd's Oral Poetry Performance Tradition

As can be seen in the figure above, shepherds have their own processesof operating traditionfor their performance. This shows that using oral poetry, the performer conveys the message to the audience based on the local cultural laws, operating formulas, conditions, and context.

Therefore, there are skilled people who perform many types of poetry. These people are also accepted by the community and are highly esteemed. Dorson (1972) argues that public poetry is created by famous and talented people. In the community where the study focuses, shepherd's poems are performed in groups, individually and in pairs. There are poets who are known for performing in a variety of ways. These performers are known locally as "prophets." This name does not apply to all shepherds.

Coming to the main focus of the study known as shepherd's oral poetry, it needs performance to listen andto pay attention to the words of shepherds. In shepherding place, shepherds while keeping the chattels in pasture, they used to sing, brag, and perform different melodies. During field observation around the study areas, the author observed that they performed these operations in various occasions. These occasions for their performance includes in the morning and evenings, when watering their cattle, take caring of cattle etc.often on their own initiative, or asked to do so.During this time, they sing a variety of hymns, songs, and lyrics individually, in pairs, and in groups. During the field observation, the author saw them moving from song to chant or bragging and dance to songduring their performance.

Generally,to study on oral poetry,the researcher must observe its performance in a contextual setting. Therefore, during performance, the activity of each action for instancewho, why, when, where, how, for whom and so on must be observed intentionally. It has been proven that the performances of the shepherd's oral poetry, chosen for study are as described above.

\subsection{Creativity}

Howoral poetry iscreated? It can be created by memorizing oral poems, creating new poems based on context, or modifying the existing ones. During performance the performer can create new verses and poems by following the melody schemeof the pre-existing oral poems. This is because the performer changes the existing lyrics to motivate the audience based on the their needs, or to prolong the performance and to express the current changes as the audience's attitude and lifestyle changes from time to time. This characteristic of change is often seen in oral poems performed in the study area.

In this regard, Finnegan (1977) explained that oral poetries could be composed in different ways during performance. Of these, memorizing, right there, and contemplation are the most important ones. Composition strategies by memorization are ways of presenting a poem that has already been performed previously by the 
performer without missingthe contents during performance. Whereas creating poems live on the stage, is the process of improving and composition of oral poem by modifying and adding new ideas of his style on the previously performed poem depending on the real performance situation. On the other hand creating oral poem by concentration is the style by which the performer stimulated by the inspirational issues (protagonist) to compose oral poetry. The uniqueness in oral poetry composition isthat, as far asit can re-create new ideas based on context. However, if it is created and the structure is memorized, it can be performed without any change. But due to prolonged time, forgetting and for contextualization reason there is less opportunity for creating oral poetry without change in words or sentences.

With regard to the shepherd's oral poetry which waschosen for study,although the shepherds presents several oral poems while they take care their cattle in grazing land, the general demonstration and composition style is similar as described above. This is because during memorization a poem presented in different places and occasion in which the whole content presented could not be as such easy. Therefore, a number of oral poems are composed following the styles or techniques described above.

Following the summary of composition of oral poetrydescribed above, let us look at the composition ofShepherds' Poetry. According to Nuriye Gashaw and Endris Youssef (the key informants) narrations, the shepherds hear new oral poem on different occasions in the form of chant, bragging (uttering war boasts), acclaim,local songs etc. and memorized it. Then they sing these oral poems again while they take caring their cattle in the field. They point out thatthey heardchants and bragging in particular from the local community.

Shepherds in Legambo Woreda not only memorize and present oral poems, but also theyhave made changes words, phrases, and verses (rhymes) and create poems on the basis of various occasions. In this regard, Nuriye Gashaw said that we created many of the poems by listening to what have been said by our families, and what we have seen from the actual situation. Besides, Nuriye added that when we spend time together in the field to look after our cattle with our friends we have the opportunity to see various issues and to play; hence, we can create oral poems and present them turn by turn and familiarize ourselves.

As mentioned above, the shepherds of Legambo Woreda not only memorize their poems but also create them based on various occasions. During field observation in Gimba and Tulu Awliya, the author noticed that,they perform poems used to describe about epoch (era, period) in pairs; the poem presented by one was modified and/or recreated base on the contemporary contextual settings. Therefore, it is possible to assume that there was a slight or complete change on oral poems. This can bring about changes in words, phrases, verses, themes, and the like.For example, let's look at the following oral poem:

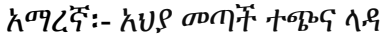

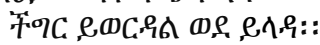

$$
\begin{aligned}
& \text { English; Coming is the donkey carrying Taxi,Lada } \\
& \text { Hardship is pouring to the Ilada. }
\end{aligned}
$$

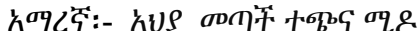

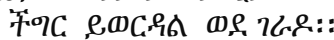

$$
\begin{aligned}
& \text { English; Coming is the donkey carrying the comb } \\
& \text { Pouring is hardship to the Gerado }
\end{aligned}
$$

When we look at these two twin poems, we can see a change in words and a change in content. In this poem, based on two local settlements, called Iilada and Gerado, shepherds describe about the upcoming challenges using their own oral poems. As a result, to predict about the future problemthey use rhyme "Coming is the donkey carrying Taxi, Lada" and the other one "Coming is the donkey carrying the comb" and by replacing different words/phrases they made change in the content of the poem. This shows that using their suitable contextual settings, shepherds prophesied, about "what will happen in the future."

Generally it indicates that shepherds create oral poetr by memorizing poems written by themselves or by someone else and modifying them to fit them into the contextual settings.

\subsection{Transmission}

The third verbal criterion of oral poetry is its oral transmission or verbal dissemination. This indicates that, the poems that have been created orally have been transmitted down from generation to generation and from place to place. In this case, however, it should be assumed that the transmission depends on the performance. This is because oral poetry created in soul/mind and transmitted orally; if the person who created ithas got no social and other opportunity to present and transmit it, the poem could be buried with the person when he died. Therefore, the survival of the transmission is strongly related to the performance.

According to Finnegan (1977) oral poems have been modified from time to time and, from place to place, without altering their content. The reason for this is that poems can be transmitted in the same form and content at different circumstances, times and places. An example of this is human's ability to memorize an idea. It is well-known that oral poetry in one's mind are passed from one to another. In this case, the original form may be changed and re-presented. 
Let's take a look at the Legambo Woreda shepherd's poem transmission as described above. Ibrahim Teshome explained about where the shepherds first get their poetry; he said that "severalpoems can be obtained from chant, bragging (uttering war boasts), acclaim, local songs, relating to what they heard and what they saw, when they sing in neighborhood while they look after cattle in the grazing land." According to him, the poems come from family, friends, the local community and themselves.On the other hand, the shepherds of Legambo Woreda create different oral poetry in one context. Let's look at the following oral poems as evidence:

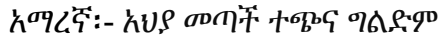

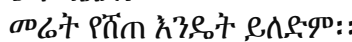

English; Coming is the donkey carrying a piece of cloth How unfortunate one who sold away his plot of land.

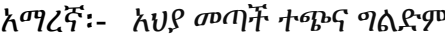

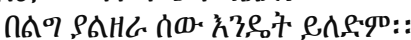

English; Coming is the donkey carrying a piece of cloth

To cover the body below the waist

How unfortunate one who does not cultivate in the fall.

When we examine the two twin poems above, they have the same content. However,by harmonizing with the contextual setting, the poems can tell us about the suffering of a person who sold his plot of land, and about the one who didn't sow his plot by himself. As we can see in the above poems, with the verse"Coming is the donkey carrying a piece of cloth" just by changing phrase they created oral poems having different contents without changing the context. This shows that just as they memorize what they hear, they also make adjustments to fit the context.

\section{Result and Dissection}

Even though they have a wide range of contents, only oral poems that have critic contents have been analyzed as an example. Categorization of oral poems conducted based on the major topics that can show the main points of the study, and by incorporating the other subtopics under these main themes. In this regard, George \& James (1995) argue that it is important to combine and analyze the performance and contexts that contribute to the creation of oral poems. Besides, these authors said that in order to analyze and explain the contents of the oral poems, it is wise to see the contextual settings and reasons that contributed for the composition of these oral poems.

Thus, descriptions provide an appropriate and convincing analysis by looking at and considering the cultural, social and personal contexts as well as opportunities for analyzing the content of the oral poems. Based on this idea, the author analyzed the content of oral poems based on the critical examination of the contextual settings of the lyrics and aligning them with the real world.

Selected poems for analysis are also critic poems that highlight the topic at hand. As a result, five exemplary oral poems were selected for analysis. Accordingly, the content analysis was as follows.

\subsection{Critic Oral Poetry}

As part of the community, the shepherds of LegamboWoreda criticize the daily social, economic and political (administrative), which are bad or good activities using their oral poems. In this way, they criticize and condemn the system of government in various period, women's rights equality, and other issues using their oral poems.

In Ethiopia, different kings and leaders have been in power for centuries. The weaknesses and strengths of the administrative system of these leaders have been criticized by their poems. As a result, they portrayed their tragic and bad actions in local songs, chanting,bragging and other verbal poems. They criticized the land tenure system since King Haile Selassie till now as follows;

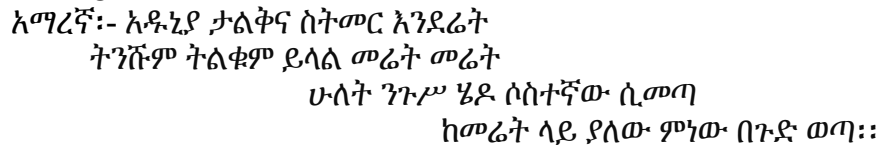

English; As the wealth finishes off, it is sour

Obsessed are the young and the old with plots of land

Gone are two regimes, and the third is in its term,

So thoughtless are rulers on issues of land.

As we can see from the verse above, there were people who were in a state of bliss and enjoyment, but with the word "wealth" we can understand that they lost their land and wealth. Hence, over time, their wealth and possessions have vanished. According to the poet, they were able to cultivate a large "area of land" in the past, but they blamed the current government for giving them less land and less wealth; and they were unable to live as they were before, after the EPRDF came in to power. Moreover, he criticized the EPRDF's administrative system, citing the merits of the previous two regimes. They highlighted the level of hardship, suffering, and they 
blame the inability of the regimes to bring back their previous happiness. They indicated their feeling with the verse, "So thoughtless are rulers on issues of land." They expressed their displeasure due to the lack of a satisfactory response to their demands for agricultural land and the loss of their livelihood in the rhyme, "Obsessed are the young and the old with plots of land." They said that, there is still no one to blame for their problems and they portrayed it with bitterness.

As the majority of the community calls their "country," with female sex; LegamboWoreda shepherds call the EPRDF as "female." In connection with this, to criticize the land tenure system,they said that she is called a king and that she looks like an emperor.

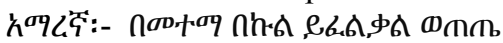

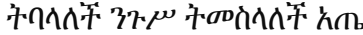

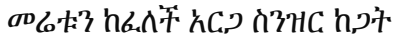

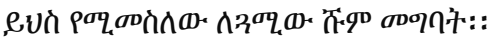

English; Billy-goats are streaming via Mettema

It is called a queen like an emperor

and she distributes tiny lands

This is being subjected to the rulers.

In Ethiopian's culture, the desert or bush is the hiding place for someone who snored (refuse to accept the ruling government system). During their stay in the desert, rebels disturb the local community in search of food, clothing, and weapons. They also snatched (took these things from the community by force). Hence, the poet described the current ruling bodies, and said that "Billy-goats are streaming via Mettema" to describe their previous disturbance (harassing) of the community. In this verse the poet transmits his message in connection with"Billy-goats," which are aggressive, forceful, and violent in characters. The shepherds, in their oral poetry, use the above verse as a confirmation to give this behavior for the EPRDF government who came to power from the direction of "Mettema".

In his oral poetry the poet use the rhyme"It is called a queen like an emperor" to describe, this disturbing and dangerous rebels who wears the royalty mask. The poet explained that they were given very little land, represented by the size of the thumb to the middle finger and even less with his verse called "And she distributes tiny lands." In the poem, the poet also raises the question of land tenure system and rights under the rhyme of "This is being subjected to the rulers." This seems to indicate that the system is worked with ill will and badly that denied the rights of citizens.

These are not the only criticism of the EPRDF regime. Shepherds are also condemning and criticizing things that are pretending is if they are good, but which are bad in reality. Among these are women's equal rights are best examples. They say that this women's equality right was not the case before, but still the women are not being using it fairly. For example, the Shepherd Kebede Faris sang the following poem:

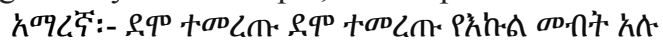

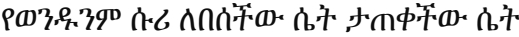

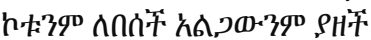

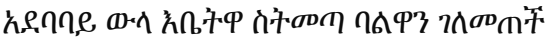

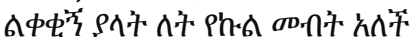

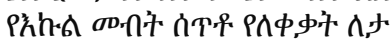

T.

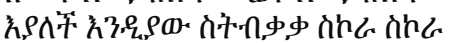

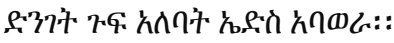

English; So they are elected more and more reportedly for equality

The female wears trousers like the male

She too wears the coat, and takes over his place

Upon returning from office, she shouts at her husband

She says we are equal, asking him to let her go

And if he lets her go to enjoy equality

She holds offices and possesses lands

And I was so proud of her, but she has caught AIDS.

In this poem, they show that when women come back home from the outside, they lose the respect they once had for their husbands. The poet use the verse "And I was so proud of her, but she has caught AIDS" to indicate the women unfair exercises of their recently obtained equality right which have a failure consequence. With regard to dressing style, women who used to wear old local dresses, now they said that they are now entitled to wear equal trousers and coats as men, and that they are proud of their equal share of wealth when they are in conflict with their husbands and the shepherds criticize that this character resulted in big crisis and make them vulnerable for disease.

Another social critique to be raised is marriage. In the Legambo area, in the past, a wife was nominated by a family. An appropriate girl would be nominated for the son based on the examination of her family back ground, 
wealth; then elders could be sent to ask for marriage in a cultural system called "give me your daughter for my son," and the marriage is consummated. This system has been called a "harmful culture" and banned recently. At present, women have a great deal to do with women's rights. Nowadays, to modernize marriage it is not uncommon for people who married and divorce. The narrators of the poem also expressed this idea in their poems:

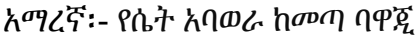

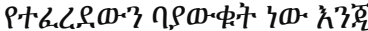

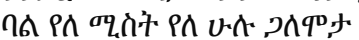

$$
\begin{aligned}
& \text { 市. }
\end{aligned}
$$

English; If the women master is proclaimed,

They do not know what has been pronounced

No wife, no husband, they are without them.

And where can marriage be found.

According to the poem, they condemn prostitution by associating modernity with modern-day backwardness. They also criticize why marriages fail.

In ancient Ethiopia, various emperors ruled over the people under different regimes. They all had their own committee or Kebele chairperson, and the current government also appointed its own chairperson. The poet said that these chairmen did nothing for the shepherds but for themselves using the following oral poem.

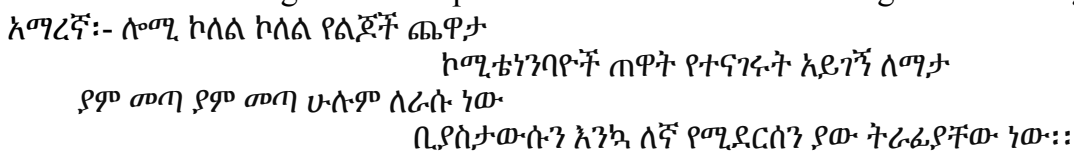

\section{English; The rolling lemon, play of children}

The so called committee spoken at the dayand changed at night

Whoever comes to rule, they seek own benefits

In case they think of us, that is the leftover

As can be seen in verse nine, the work of the government committees is linked to the games that children enjoy in their childhood. In his lyrical poem, he found the role of committees in society as meaningless and this is indicated with the verse "The rolling lemon, play of children." This shows that the roles of the committee have nothing to do with the society other than entertainment as comparable with children's game. The poet linked the work of the committees to the immature minds of children and spoke of their futility. In the verse "The so called committee spoken at the day and changed at night" the poet joked at them with the phrase "The so called committee" and he said that they lie, have no firm stand and reckless. As can be seen from the oral poem, the government bodies in power think and work for the community after they successfully satisfied their advantages and needs. The poet indicated such local community's pain and bitterness with his verse "In the case they think of us that is the left over."

According to the poem, the people in power show sympathy for others only after they have served their own interests and needs. In his poem "The so-called committee", the narrator asserts that they did not stand for the people but for their own interests and that they all ran for their own interests and not for the people when they came to power. The poet's narration was supported and confirmed by the verse "Whoever come to rule, they seek own benefits" Because even though they make a rule of law, they adjust laws, rules and directions to fit for their own advantage. If they think the proclamation is not comfortable for their own benefit they can change it and declares a new one immediately over night. In such a way Legambo Woreda shepherds criticize the government systems, explain their internal feeling, anger and bitterness via their oral poetries.

\section{Conclusion and Recommendation}

The finding of the study showed that shepherds in Legambo Woreda compose oral poems by themselves, either memorized poems that has been created by others or modifying them to make appropriate for the contextual settings. Their performance found to be in three ways i.e. individually, in pairs and in groups. It has also been shown that they convey what they have heard and make changes of words, phrases, verses, and the like to fit the context.

Shepherds while they take care their cattle in grazing filed, raise various topics and have composed their oral poems which are essentially critic, and they sing about administrative issues, laziness, joy and sorrow, success and failure, gain and loss, satiety, hunger and the right to equality; they sing and raise various issues. Among these were the government's violation of human and democratic rights and its negative impact on its citizens.

In the study it has been observed that shepherds are influential in the culture and are known for their preconceived notions in the social life of the community. With their oral poems they raised focal ideas set 
direction and known for their prophesy ideas to forecast the future time.

In addition to the poems that shepherds create in the place of shepherding, they also receive poems of praise and lamentation at weddings, mourning, and feasting; in mediation and similar situations, presented by elders. They perform their oral poems to transmit these ideas while they look after their cattle in the grazing land. This indicates that they often hear, memorize, and remember from other community members and perform their oral poems.

In general, the oral poems performed by shepherds in the pastoral area are the local spectacles that directly or indirectly reflect the philosophy, attitudes, and interests of the community. But during the field work, the author have seen and observed that these poems, especially the critic ones, are under pressure by various government agencies to prevent them from being widely used in the community.

The author conclude the study by suggesting that these shepherds' poems are not only describe the current state of affairs but also reflect the many philosophies of life. Hence, the respective bodies (academic institutes) should collect these oral poetries regularly and should be preserved in archives

\section{Reference}

Bauman R. 1977. Verbal Art as performance. Waveland: University press.

Bauman R. 1986. Story, Performance and Event. Cambridge University press.

Ben-Amos D. 1982. Folklore in Context. South Asian Publishers. New Delhi Madres.

Ben-Amos D. 1993. "Context" in Context. Western Folklore vol. 52, No. 2/4, Theorizing Folklore towards New perspective on the politics of culture.

Desta T. 1970. New Amharic Dictionary. Artistic printing house, Addis Ababa.

Fekade A. Oral rhetoric. 1984. Ethiopian Languages and Literature Magazine. No. 2 Addis Ababa, Addis Ababa University Press.

Fekade A. 1993. Directory of Oral Literature. Alpha Publishers, Addis Ababa.

Fekade A. 1998. Unheard Voices Drought, Famine and God in Ethiopian Oral Poetry. Addis Ababa University Press.

Finnegan R. 1970. Oral Literature in Africa. Nairobi Oxford University Press.

Finnegan R. 1977. Oral Poetry its nature, significance and social context. Cambridge: Cambridge University Press.

Finnegan R. 1992. Oral Tradition and the verbal arts. A Guide to research practices. London and Now York.

Goldstin, K.S. 1964. A guide for field works in Folklore. Pennsylvania Harbored, Folklore Association Inc.

George, Robert A. and Michael own Jones. 1995. Folkloristic an Introduction. Bloomington, Indian University press.

Getie G. 2000. Peasants and the Ethiopian Agricultural Producers" Cooperative and their Reflections in Amharic Oral Poetry-A case study in YetNora, East Gojjam. 1975-1991 Volume 7, Hamburg Lit Verlag Munster

Kssate B. 1970. Amharic Dictionary. Artistic Printing House, Addis Ababa.

Legambo Woreda. 2003. Annual Work Report. Culture and Tourism office, leganbo.

Telethon M. January 2002. A brief overview of Legambo Woreda. Legambo woreda press.

Mac D. 2003. A Field work collection of Oral Literature in Richard Dorson (Compiled by Fekade Azeze,).

Mac H, Robert, ed. 1993. The New Encyclopedia, $15^{\text {th }}$ ed. Vol. 9. USA, the University of Chicago.

Martha C. Sims 2005. Living Folklore. An introduction to the study of people and their Traditions. Utah state university press.

Miruka O. 1994. Encounter with Oral literature. Nairobi, East Africa Educational Publishers Ltd.

Okpewho I. 1992. African oral literature backgrounds, characters and continuity. Bloomington. Indiana, University press.

Richard, M.D. 1972. Folklore and Folk life an Introduction. Chicago and London: Press. 